Article

\title{
Analysis and Design of High-Efficiency Bidirectional GaN-Based CLLC Resonant Converter
}

\author{
Yuanjun Liu, Guiping Du *, Xueyi Wang and Yanxiong Lei
}

School of Electric Power Engineering, South China University of Technology, Guangzhou 510641, China; 201721014332@mail.scut.edu.cn (Y.L.); 201630236276@mail.scut.edu.cn (X.W.);

201720113760@mail.scut.edu.cn (Y.L.)

* Correspondence: gpdu@scut.edu.cn; Tel.: +86-13926460600

Received: 28 August 2019; Accepted: 9 October 2019; Published: 12 October 2019

\begin{abstract}
A bidirectional CLLC resonant converter (CLLC-BRC) based on GaN transistors is analyzed and designed in this paper. Similar resonant topologies are listed and commented on, with the CLLC topology showing competitiveness in bidirectional energy transmission. The analysis of the aforementioned converter has been provided, including the reveal of resonant frequencies of the CLLC topology and an improved zero-voltage switching (ZVS) condition with operation principles of the reverse mode and relevant parasitic parameters taken into account. The design methodology of the aforementioned converter based on pulse frequency modulation (PFM) is further discussed in detail. A prototype with a rated power of $400 \mathrm{~W}$ and a maximal operating frequency that is larger than $0.5 \mathrm{MHz}$ was built to verify the proposed design methodology. The highest conversion efficiency of the prototype was $97.02 \%$ in the forward mode, and it was $95.96 \%$ in the reverse mode.
\end{abstract}

Keywords: GaN transistors; bidirectional CLLC resonant converter; high efficiency

\section{Introduction}

Bidirectional DC/DC converters (BDCs) play an important role in many fields, including new energy generation systems, electric vehicles, aerospace power supplies and uninterruptible power supplies. An isolated type of BDC is usually accepted instead of a non-isolated one, as shown in Figure 1, since the aforementioned fields have strict requirements for safety.

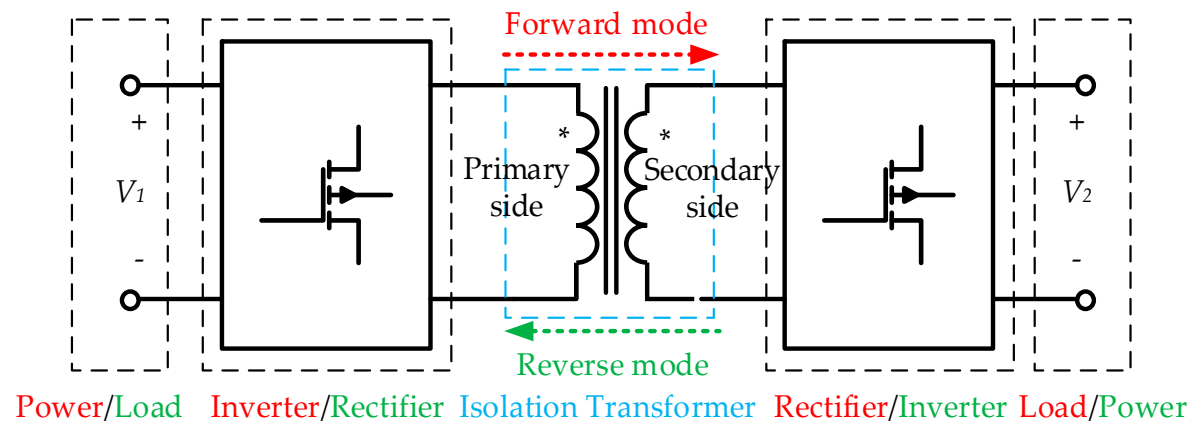

Figure 1. Structure of isolated BDC.

Many isolated BDCs focus on soft switching to reduce loss due to its high operating frequency aiming for high power density, which are mainly divided into the phase shift control type [1,2] and the resonant type [3,4]. The gain range of the phase shift control type is limited, and soft switching of the full load range is hard achieve. By contrast, the LLC resonant converter is a topology of three resonant components that can achieve zero-voltage switching (ZVS) in the inverter-side of the full 
load range without any auxiliary circuits. In order to achieve bidirectional energy transmission, the diodes of its rectifier bridge are replaced with fully controlled devices. In [5], all the topologies of three resonant components are listed, including Type-4 and Type-11, as shown in Figure 2a,b. However, similar bidirectional voltage gain characteristics cannot be obtained in the two types. For example, when the LLC resonant circuit operates in the reverse mode, it degenerates into a LC resonant circuit, with normalized dc gain below 1. In [6-12], a symmetric tank structure called CLLLC is proposed, as shown in Figure 2c. Although similar bidirectional voltage gain features are obtained, too many resonant components are used in CLLLC, which increases the volume of the converter and the error of analysis and design. What's more, the procedures of designing parameters [6] and controllers [7] are complicated, with the potential for risky operations caused by parasitic capacitance [12], leading to deviations from the design intention. In $[13,14]$, a resonant tank of four elements called CLLC is proposed, as shown in Figure 2d. In contrast to the CLLLC topology, one resonant inductor is omitted in the CLLC topology, and similar bidirectional voltage gain features are obtained. The CLLC-BRC can achieve ZVS in the inverter side of the full-load range, and zero-current switching (ZCS) in the rectifier side of a certain load range. Additionally, the range of bidirectional DC gains is expanded, leading to more flexible capacity of voltage regulation. In [14], the forward mode and the reverse mode are equivalent to Type- 4 and Type- 11 with additional capacitors respectively. However, different basic frequencies are used for the two modes, with some features in common ignored. The current research on CLLC-BRC still needs to be improved, such as calculation of resonant frequencies of the CLLC topology, more thorough soft switching condition and so on.

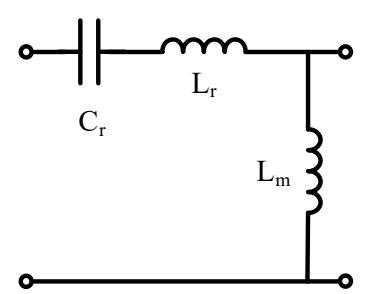

(a)

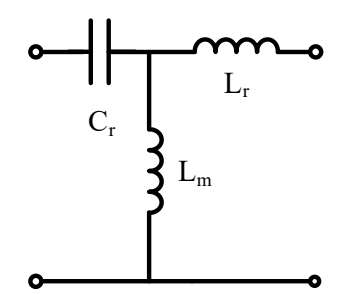

(b)

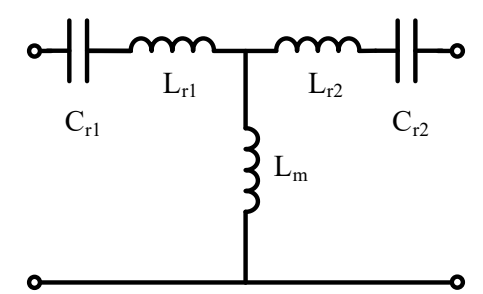

(c)

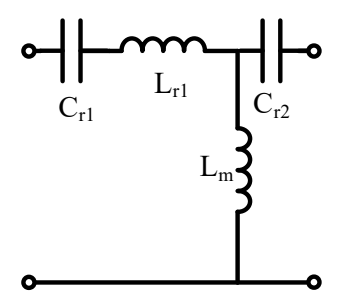

(d)

Figure 2. Structures of resonant tanks of different types. (a) Type-4, i.e., LLC; (b) Type-11; (c) CLLLC; (d) CLLC.

Moreover, with the continuous development of semiconductor technology, the third generation of wide-bandgap semiconductor devices, including gallium nitride $(\mathrm{GaN})$ devices and silicon carbide ( $\mathrm{SiC})$ devices, have been developed to help BDCs achieve higher frequency, higher power density, and higher efficiency, replacing conventional devices like Si MOSFETs. A summary of the material characteristics of these devices is shown in [9]. GaN has higher energy gap and electron velocity in contrast to SiC and $\mathrm{Si}$, and thus GaN transistors possess better performance of lower on-resistance, faster switching speed, lower parasitic parameters, lower reverse recovery loss and so on. GaN transistors are suitable for even MHz-level operating frequency occasions that are difficult for application of SiC devices with high efficiency. It is well expected that GaN transistors deserve to replace other devices in low or medium power occasions. However, $\mathrm{GaN}$ transistors have a lower driving voltage threshold than $\mathrm{SiC}$ devices and thus have a high requirement for designing driving circuits to prevent wrong conduction. Meanwhile, GaN transistors have a larger reverse conduction voltage drop than SiC devices when no driving voltage is supplied, and thus synchronous rectification (SR) must be applied in the rectifier-side of BDC, whose accuracy affects the quality of output voltage and efficiency. Due to these problems, it is meaningful to study the application of GaN transistors in different BDC topologies that have already been equipped with MOSFETs. In [15-20], GaN transistors are applied to the conventional LLC resonant converter. However, it is hard to meet the bidirectional application requirement with the limitation of the LLC topology in the reverse mode. In [9], GaN transistors were applied to the bidirectional CLLLC resonant converter with parameters based on the design methodology proposed 
in [6]. However, complicated principles and the high design requirements of the CLLLC converter disturb the successful application of $\mathrm{GaN}$ transistors. Current solutions of replacing all conventional switching devices with GaN transistors in BDCs are still unsatisfying.

Therefore, this paper focuses on CLLC-BRCs of high operating frequency and high efficiency based on GaN transistors. In Section 2, the characteristics of CLLC-BRC are discussed in detail based on its operation principles, including the solution of resonant frequencies, definitions of auxiliary parameters and an improved ZVS condition of the inverter-side switches. In Section 3, the design procedures of GaN-based CLLC-BRC based on PFM are presented with assistance of the previous analysis. Then, the structure of the prototype and experimental results are shown in Section 4. Finally, conclusions are made in Section 5.

\section{Analysis of Bidirectional CLLC Resonant Converter}

The structure of GaN-based CLLC-BRC is shown in Figure 3. In [14], the operation principles of both the forward mode (MT-4 mode) and the reverse mode (MT-11 mode) of CLLC-BRC have been illustrated in detail, which thus will not be restated in this paper. However, different reference frequencies were used in the normalized dc gain curves of the two modes in [14], which conceals some critical features of CLLC topology, like the same resonant frequencies possessed by the two modes. Based on the first harmonic approximation (FHA) method, the following analysis is given.

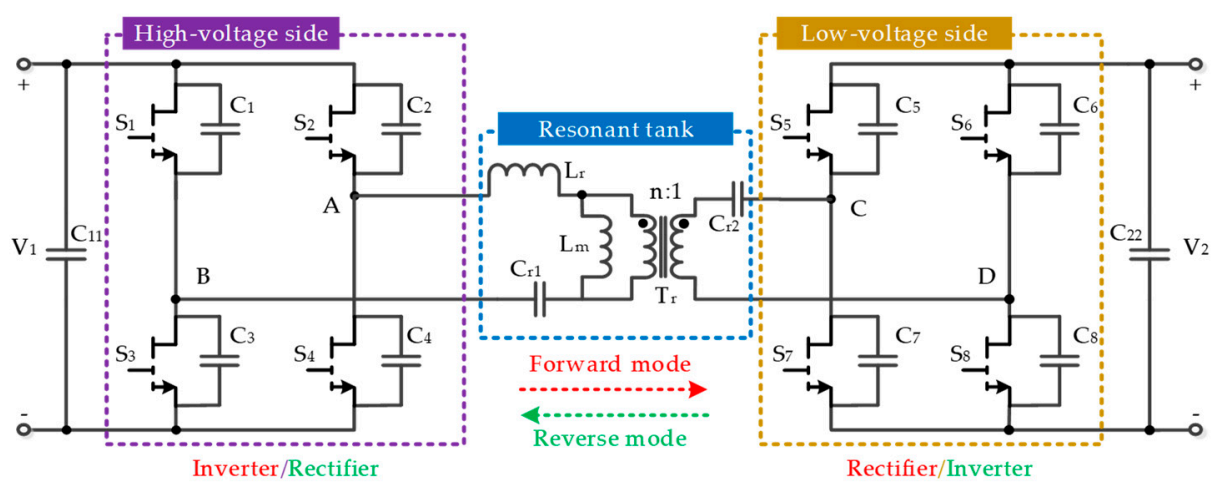

Figure 3. Structure of GaN-based CLLC-BRC.

\subsection{Resonant Frequencies of Bidirectional CLLC Resonant Converter}

The equivalent circuit of the forward mode is shown in Figure $4 a$, where $C_{r 2 e}=\frac{C_{r 2}}{n^{2}}$ is the normalized capacitor of $C_{r 2}$, and $R_{e f}=\frac{8}{\pi^{2}} n^{2} R_{L 1}$ is the normalized equivalent $A C$ resistance of the forward-mode load $\mathrm{R}_{\mathrm{L} 1}$. It can be further converted into the topology in Figure $4 \mathrm{~b}$ based on Thevenin's theorem, where the equivalent tank voltage $V_{1 \text { tank }}$ and the total tank impedance $Z_{1 \text { tank }}$ can be derived as:

$$
\begin{gathered}
\mathrm{V}_{1 \text { tank }}=\mathrm{V}_{1} \frac{\omega_{\mathrm{s}} \mathrm{L}_{\mathrm{m}}}{\omega_{\mathrm{s}} \mathrm{L}_{\mathrm{m}}+\omega_{\mathrm{s}} \mathrm{L}_{\mathrm{r}}-\frac{1}{\omega_{\mathrm{s}} \mathrm{C}_{\mathrm{r} 1}}} \\
\mathrm{Z}_{1 \text { tank }}=\frac{1}{j \omega_{\mathrm{s}} \mathrm{C}_{\mathrm{r} 2 \mathrm{e}}}+\mathrm{j} \omega_{\mathrm{s}} \mathrm{L}_{\mathrm{m}} /\left(j \omega_{\mathrm{s}} \mathrm{L}_{\mathrm{r}}+\frac{1}{j \omega_{\mathrm{s}} \mathrm{C}_{\mathrm{r} 1}}\right)=\mathrm{j} \frac{\mathrm{L}_{\mathrm{m}} \mathrm{L}_{\mathrm{r}} \mathrm{C}_{\mathrm{r} 1} \mathrm{C}_{\mathrm{r} 2 \mathrm{e}} \omega_{\mathrm{s}}^{4}-\left(\mathrm{L}_{\mathrm{m}} \mathrm{C}_{\mathrm{r} 1}+\mathrm{L}_{\mathrm{m}} \mathrm{C}_{\mathrm{r} 2 \mathrm{e}}+\mathrm{L}_{\mathrm{r}} \mathrm{C}_{\mathrm{r} 1}\right) \omega_{\mathrm{s}}^{2}+1}{\omega_{\mathrm{s}}^{2} \mathrm{C}_{\mathrm{r} 1} \mathrm{C}_{\mathrm{r} 2 \mathrm{e}}\left(\omega_{\mathrm{s}} \mathrm{L}_{\mathrm{m}}+\omega_{\mathrm{s}} \mathrm{L}_{\mathrm{r}}-\frac{1}{\left.\omega_{\mathrm{s}} \mathrm{C}_{\mathrm{r} 1}\right)}\right.}
\end{gathered}
$$

where $\omega_{\mathrm{s}}=2 \pi \mathrm{f}_{\mathrm{s}}$ and $\mathrm{f}_{\mathrm{s}}$ is the operating frequency of CLLC-BRC. 


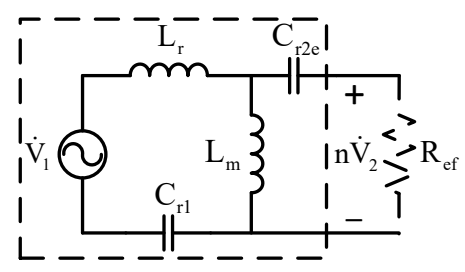

(a)

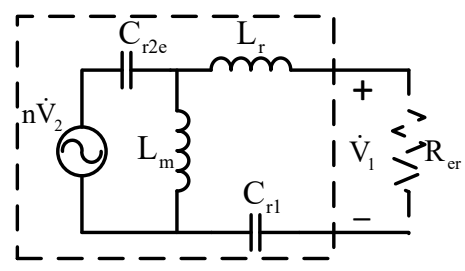

(c)

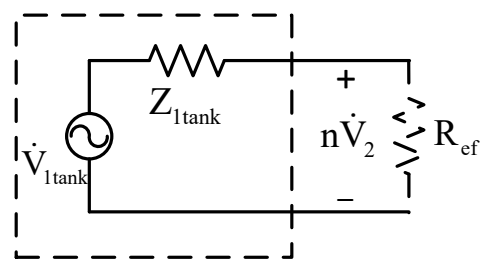

(b)

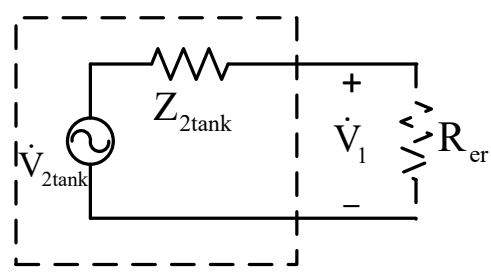

(d)

Figure 4. Equivalent circuits of the forward mode and the reverse mode. (a) FHA circuit of the forward mode; (b) Thevenin equivalent circuit of (a); (c) FHA circuit of the reverse mode; (d) Thevenin equivalent circuit of (c).

The total impendence is in the state of pure resistance when the CLLC-BRC operates at the resonant frequencies. That is to say, $Z_{1 \operatorname{tank}}=0$, i.e.:

$$
\mathrm{L}_{\mathrm{m}} \mathrm{L}_{\mathrm{r}} \mathrm{C}_{\mathrm{r} 1} \mathrm{C}_{\mathrm{r} 2 \mathrm{e}} \omega_{\mathrm{s}}^{4}-\left(\mathrm{L}_{\mathrm{m}} \mathrm{C}_{\mathrm{r} 1}+\mathrm{L}_{\mathrm{m}} \mathrm{C}_{\mathrm{r} 2 \mathrm{e}}+\mathrm{L}_{\mathrm{r}} \mathrm{C}_{\mathrm{r} 1}\right) \omega_{\mathrm{s}}^{2}+1=0
$$

Apparently, there exist two resonant frequencies in the forward mode, which can be defined as $\mathrm{f}_{\mathrm{r} 1}$ and $\mathrm{f}_{\mathrm{r} 2}\left(\mathrm{f}_{\mathrm{r} 1}<\mathrm{f}_{\mathrm{r} 2}\right)$. Meanwhile, the equivalent circuits of the reverse mode of CLLC-BRC are shown in Figure $4 c, d$, where $R_{e r}=\frac{8}{\pi^{2}} R_{L 2}$ is the equivalent ac resistance of the reverse-mode load $R_{L 2}$. Similarly, $\mathrm{V}_{2 \operatorname{tank}}$ and $\mathrm{Z}_{2 \operatorname{tank}}$ can be derived as:

$$
\begin{gathered}
\mathrm{V}_{2 \operatorname{tank}}=\mathrm{nV}_{2} \frac{\omega_{\mathrm{s}} \mathrm{L}_{\mathrm{m}}}{\omega_{\mathrm{s}} \mathrm{L}_{\mathrm{m}}-\frac{1}{\omega_{\mathrm{s}} \mathrm{C}_{\mathrm{r} 2 \mathrm{e}}}} \\
\mathrm{Z}_{2 \operatorname{tank}}=\mathrm{j} \frac{\mathrm{L}_{\mathrm{m}} \mathrm{L}_{\mathrm{r}} \mathrm{C}_{\mathrm{r} 1} \mathrm{C}_{\mathrm{r} 2 \mathrm{e}} \omega_{\mathrm{s}}^{4}-\left(\mathrm{L}_{\mathrm{m}} \mathrm{C}_{\mathrm{r} 1}+\mathrm{L}_{\mathrm{m}} \mathrm{C}_{\mathrm{r} 2 \mathrm{e}}+\mathrm{L}_{\mathrm{r}} \mathrm{C}_{\mathrm{r} 1}\right) \omega_{\mathrm{s}}^{2}+1}{\omega_{\mathrm{s}}^{2} \mathrm{C}_{\mathrm{r} 1} \mathrm{C}_{\mathrm{r} 2 \mathrm{e}}\left(\omega_{\mathrm{s}} \mathrm{L}_{\mathrm{m}}-\frac{1}{\omega_{\mathrm{s}} \mathrm{C}_{\mathrm{r} 2 \mathrm{e}}}\right)}
\end{gathered}
$$

When the CLLC-BRC operates at the resonant frequencies, the same reason leads to $Z_{2 \operatorname{tank}}=0$, i.e., condition (3). That is to say, the same resonant frequencies are possessed by both the forward mode and the reverse mode.

Defining $\mathrm{a}=\mathrm{L}_{\mathrm{m}} \mathrm{L}_{\mathrm{r}} \mathrm{C}_{\mathrm{r} 1} \mathrm{C}_{\mathrm{r} 2 \mathrm{e}}, \mathrm{b}=-\left(\mathrm{L}_{\mathrm{m}} \mathrm{C}_{\mathrm{r} 1}+\mathrm{L}_{\mathrm{m}} \mathrm{C}_{\mathrm{r} 2 \mathrm{e}}+\mathrm{L}_{\mathrm{r}} \mathrm{C}_{\mathrm{r} 1}\right)$ and $\mathrm{c}=1$, with permanent $\mathrm{b}^{2}-4 \mathrm{ac}>$ 0 , resonant frequencies of the two modes, i.e., $\mathrm{f}_{\mathrm{r} 1}$ and $\mathrm{f}_{\mathrm{r} 2}$, can be derived from Equation (3) as:

$$
\mathrm{f}_{\mathrm{r} 1}=\sqrt{\omega_{\mathrm{s}}^{2}} / 2 \pi=\sqrt{\frac{-\mathrm{b}-\sqrt{\mathrm{b}^{2}-4 a c}}{2 \mathrm{a}}} / 2 \pi, \mathrm{f}_{\mathrm{r} 2}=\sqrt{\frac{-\mathrm{b}+\sqrt{\mathrm{b}^{2}-4 a c}}{2 \mathrm{a}}} / 2 \pi
$$

\subsection{Auxiliary Parameters}

To simplify the analysis, some critical auxiliary parameters deserve to be defined, with their expressions and meanings shown in Table 1. 
Table 1. Auxiliary parameters' definitions.

\begin{tabular}{ccc}
\hline Parameter & Expression & Meaning \\
\hline $\mathrm{Q}_{1} ; \mathrm{Q}_{2}$ & $\frac{\sqrt{\mathrm{L}_{\mathrm{r}} / \mathrm{C}_{\mathrm{r} 1}}}{\mathrm{R}_{\mathrm{er}}} ; \frac{\sqrt{\mathrm{L}_{\mathrm{r}} / \mathrm{C}_{\mathrm{r} 2 \mathrm{e}}}}{\mathrm{R}_{\mathrm{f}}}$ & $\begin{array}{c}\text { Quality factor of the forward mode and the reverse } \\
\text { mode, respectively }\end{array}$ \\
$\mathrm{C}_{\mathrm{n}}$ & $\frac{\mathrm{C}_{\mathrm{r} 2 \mathrm{e}}}{\mathrm{C}_{\mathrm{r} 1}}$ & $\begin{array}{c}\text { Ratio of resonant capacitors } \\
\text { Ratio of resonant inductors }\end{array}$ \\
$\mathrm{L}_{\mathrm{n}}$ & $\frac{\frac{\mathrm{L}_{\mathrm{r}}}{\mathrm{L}_{\mathrm{r}}}}{2 \pi \sqrt{\mathrm{L}_{\mathrm{r}} \mathrm{C}_{\mathrm{r} 1}}}$ & $\begin{array}{c}\text { Basic frequency } \\
\mathrm{f}_{\mathrm{n}}\end{array}$ \\
$\mathrm{f}$ & $\frac{\frac{\mathrm{f}_{\mathrm{s}}}{\mathrm{f}_{\mathrm{n}}}}{2 \pi \sqrt{\left(\mathrm{L}_{\mathrm{r}}+\mathrm{L}_{m}\right) \mathrm{C}_{\mathrm{r} 1}}} ; \frac{1}{2 \pi \sqrt{\mathrm{L}_{\mathrm{m}} \mathrm{C}_{\mathrm{r} 2 \mathrm{e}}}}$ & $\begin{array}{c}\text { Normalized operating frequency } \\
\text { ferward mode and the reverse mode, respectively }\end{array}$ \\
\hline
\end{tabular}

Therefore, based on the FHA method, normalized dc gain $G_{f}$ of the forward mode and $G_{r}$ of the reverse mode can be expressed respectively as:

$$
\begin{aligned}
& \left|G_{f}\right|=\left|\frac{n V_{2}}{V_{1}}\right|=\left|\frac{f^{2}-1}{L_{n} \cdot f^{2}}+1+j\left\{\frac{Q_{1} \cdot\left[C_{n} L_{n} f^{4}-\left(C_{n} L_{n}+L_{n}+1\right) f^{2}+1\right]}{C_{n} L_{n} f^{3}}\right\}\right|^{-1} \\
& \left|G_{r}\right|=\left|\frac{V_{1}}{n V_{2}}\right|=\left|1-\frac{1}{C_{n} L_{n} f^{2}}+j\left\{\frac{Q_{2} \cdot\left[C_{n} L_{n} f^{4}-\left(C_{n} L_{n}+L_{n}+1\right) f^{2}+1\right]}{f^{3} L_{n} \sqrt{C_{n}}}\right\}\right|^{-1}
\end{aligned}
$$

Meanwhile, Equation (3) can be simplified based on Table 1 as:

$$
C_{n} L_{n} f^{4}-\left(C_{n} L_{n}+L_{n}+1\right) f^{2}+1=0
$$

Defining $p=C_{n} L_{n}, q=-\left(C_{n} L_{n}+L_{n}+1\right)$, the normalized resonant frequencies $f_{1}$ and $f_{2}$ can be expressed as:

$$
f_{1}=\sqrt{\frac{-q-\sqrt{q^{2}-4 p}}{2 p}}, f_{2}=\sqrt{\frac{-q+\sqrt{q^{2}-4 p}}{2 p}}
$$

With the help of auxiliary parameters, more simplified analysis results were obtained. In addition, normalized DC gain is only decided by $\mathrm{Q}_{1}, \mathrm{Q}_{2}, \mathrm{C}_{\mathrm{n}}$, $\mathrm{L}_{\mathrm{n}}$ and $\mathrm{f}$, which will be discussed in the following design methodology in detail.

\subsection{Improved Zero-Voltage Switching Condition for Bidirectional CLLC Resonant Converter}

In order to realize ZVS of the inverter-side switches, their parasitic capacitors should be completely charged and discharged within the dead time. In contrast to ZVS conditions in [6,14], an improved condition of ZVS with relevant parasitic parameters and dead-time processes of both the forward mode and the reverse mode taken into account is provided in this paper. Based on the operation principles of CLLC-BRC, the following assumptions were made:

1. The operating frequency $f_{s}$ is very close to the resonant frequency $f_{r 2}$ aiming for optimal operation, with continuous current in the inverter side;

2. The process of charging and discharging parasitic capacitance is extremely short with constant inverter-side current taken into account.

Figure 5a shows the critical waveforms about charging and discharging parasitic capacitance in the forward mode. Based on the FHA method, the initial inverter-side current in the dead time of the forward mode, i.e., the constant current in the dead time, can be expressed as:

$$
\mathrm{I}_{\text {dead } \_\mathrm{f}}=\frac{1}{2} \int_{0}^{\mathrm{t}_{1}} \mathrm{n} \frac{\mathrm{V}_{2}-\mathrm{u}_{\mathrm{Cr} 2}}{\mathrm{~L}_{\mathrm{m}}} \mathrm{dt}, \mathrm{u}_{\mathrm{Cr} 2}=\mathrm{U}_{\mathrm{Cr} 2} \cos \left(2 \pi \mathrm{f}_{\mathrm{s}} \mathrm{t}+\varphi\right)
$$


where $\mathrm{U}_{\mathrm{Cr} 2}$ is the peak voltage on $\mathrm{C}_{\mathrm{r} 2}$.

As for the rectifier-side current $\mathrm{i}_{\mathrm{Cr} 2}$, it is clear that:

$$
\mathrm{i}_{\mathrm{Cr} 2}=\mathrm{C}_{\mathrm{r} 2} \frac{\mathrm{du}_{\mathrm{Cr} 2}}{\mathrm{dt}}, \mathrm{i}_{\mathrm{Cr} 2}(0)=0
$$

Therefore, $\mathrm{I}_{\text {dead_f }}$ can be estimated from (11 12) as:

$$
\mathrm{I}_{\text {dead_f }}=\frac{\mathrm{nV}_{2} \mathrm{t}_{1}}{2 \mathrm{~L}_{\mathrm{m}}} \approx \frac{\mathrm{nV}_{2}}{4 \mathrm{f}_{\mathrm{s}} \mathrm{L}_{\mathrm{m}}}
$$

Figure $5 \mathrm{c}$ shows the equivalent circuit of charging and discharging parasitic capacitance in the forward mode, where $C_{1}=C_{2}=C_{3}=C_{4}=C_{o s s 1}$ with $C_{\text {oss1 }}$, that is the parasitic capacitance of the high-voltage side switches, and $\mathrm{C}_{5}=\mathrm{C}_{6}=\mathrm{C}_{7}=\mathrm{C}_{8}=\mathrm{C}_{\mathrm{oss} 2}$. with $\mathrm{C}_{\mathrm{oss} 2}$ that is the parasitic capacitance of the low-voltage side switches, and $\mathrm{C}_{\mathrm{Tr}}$ is the equivalent parasitic capacitance of the transformer. In order to guarantee ZVS, it is required that:

$$
\frac{I_{\text {dead_f }} t_{\text {dead }}}{C_{\text {eff }}}>\Delta u_{A B}=2 V_{1}
$$

where $C_{\text {eff }}=C_{o s s 1}+C_{T r}+C_{o s s 2} / n^{2}$ is the equivalent capacitance of the inverter-side in the forward mode.

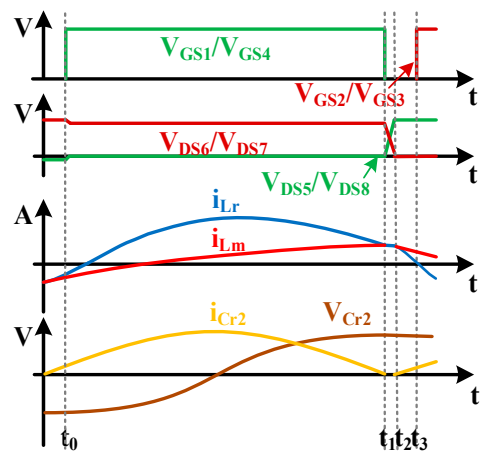

(a)

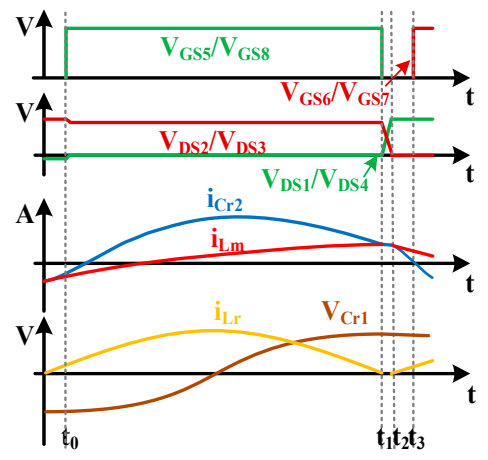

(b)

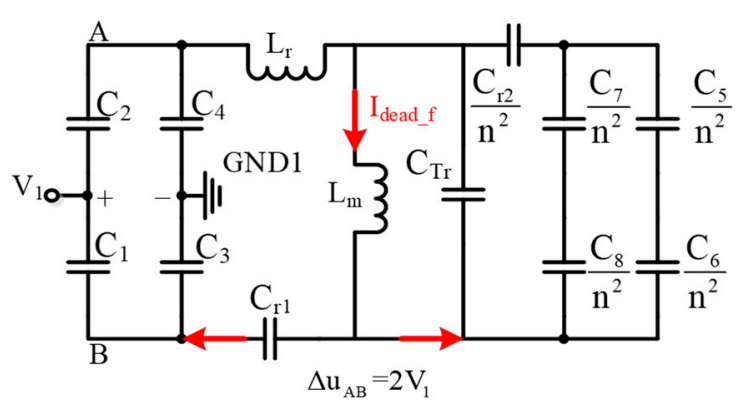

(c)

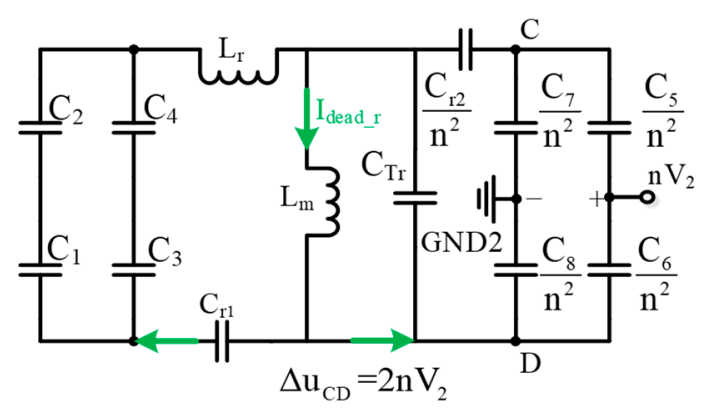

(d)

Figure 5. Analysis diagram of ZVS. (a) Critical waveforms of the forward mode; (b) critical waveforms of the reverse mode. (c) Charging and discharging circuit of the forward mode; (d) charging and discharging circuit of the reverse mode.

Similar analysis was done for the reverse mode. Figure $5 b$ shows the critical waveforms about charging and discharging parasitic capacitance in the reverse mode. The constant inverter-side current in the dead time of the reverse mode can be expressed as:

$$
\mathrm{I}_{\text {dead } \_r}=\frac{1}{2} \int_{0}^{\mathrm{t}_{1}} \frac{\mathrm{V}_{1}-\mathrm{u}_{\mathrm{Cr} 1}-\mathrm{u}_{\mathrm{Lr}}}{\mathrm{L}_{\mathrm{m}}} \mathrm{dt}, \mathrm{u}_{\mathrm{Cr} 1}=\mathrm{U}_{\mathrm{Cr} 1} \cos \left(2 \pi \mathrm{f}_{\mathrm{s}} \mathrm{t}+\varphi\right)
$$


where $\mathrm{U}_{\mathrm{Cr} 1}$ is the peak voltage on $\mathrm{C}_{\mathrm{r} 1}$.

As for the rectifier-side current $i_{L r}$, it is clear that:

$$
\mathrm{i}_{\mathrm{Lr}}=\mathrm{C}_{\mathrm{r} 1} \frac{\mathrm{du}_{\mathrm{Cr} 1}}{\mathrm{dt}}, \mathrm{u}_{\mathrm{Lr}}=\mathrm{L}_{\mathrm{r}} \frac{\mathrm{di}_{\mathrm{Lr}}}{\mathrm{dt}}, \mathrm{i}_{\mathrm{Lr}}(0)=0
$$

Therefore, $\mathrm{I}_{\text {dead_r }}$ can be estimated from Equations (15) and (16) as:

$$
\mathrm{I}_{\text {dead_r }}=\frac{\mathrm{V}_{1} \mathrm{t}_{1}}{2 \mathrm{~L}_{\mathrm{m}}} \approx \frac{\mathrm{V}_{1}}{4 \mathrm{f}_{\mathrm{s}} \mathrm{L}_{\mathrm{m}}}
$$

Figure $5 \mathrm{~d}$ shows the equivalent circuit of charging and discharging parasitic capacitance in the reverse mode. In order to guarantee ZVS, it is required that:

$$
\frac{\mathrm{I}_{\text {dead_r }} \mathrm{t}_{\text {dead }}}{\mathrm{C}_{\text {eff2 }}}>\Delta \mathrm{u}_{\mathrm{CD}}=2 \mathrm{nV}_{2}
$$

where $C_{\text {eff } 2}=C_{\text {eff }}$ is the equivalent capacitance of the inverter-side in the reverse mode.

Therefore, the final ZVS condition of CLLC-BRC can be expressed as:

$$
\mathrm{L}_{\mathrm{m}}<\min \left\{\frac{\mathrm{nV_{2 }} \mathrm{t}_{\text {dead }}}{8 \mathrm{f}_{\mathrm{s}} \mathrm{V}_{1} \mathrm{C}_{\text {eff }}}, \frac{\mathrm{V}_{1} \mathrm{t}_{\text {dead }}}{8 \mathrm{f}_{\mathrm{s}} \mathrm{nV}_{2} \mathrm{C}_{\text {eff }}}\right\}
$$

Based on the requirements of Equation (19), $\mathrm{L}_{\mathrm{m}}$ should be set as large as possible, so as to reduce the peak of excitation current and dead-time loss. Apparently, lower parasitic capacitance benefits the realization of soft switching, which strengthens the demand for GaN transistors in CLLC-BRCs.

\section{Design Methodology of GaN-Based Bidirectional CLLC Resonant Converter}

\subsection{Design Procedures}

We take the procedures of designing the prototype as an example to illustrate the flow chart of designing GaN-based CLLC-BRC, as shown in Figure 6. Design requirements of the prototype are shown in Table 2.

Table 2. Design requirements of the prototype.

\begin{tabular}{cccccc}
\hline Direction & Rated Power & High-Voltage Side/ $\mathbf{V}_{1}$ & Low-Voltage Side/ & Output & Ripple \\
\hline Forward & $400 \mathrm{~W}$ & {$[382 \mathrm{~V}, 408 \mathrm{~V}] \mathrm{V}_{1 \mathrm{~N}}=400 \mathrm{~V}$} & {$[48 \mathrm{~V}, 56 \mathrm{~V}] \mathrm{V}_{2 \mathrm{~N}}=50 \mathrm{~V}$} & $\mathrm{I}_{2}=8 \mathrm{~A}$ & $\Delta \mathrm{I}_{2} \leq 1 \%$ \\
Reverse & $400 \mathrm{~W}$ & $\mathrm{~V}_{1 \mathrm{~N}}=400 \mathrm{~V}$ & {$[48 \mathrm{~V}, 56 \mathrm{~V}] \mathrm{V}_{2 \mathrm{~N}}=50 \mathrm{~V}$} & $\mathrm{~V}_{1}=400 \mathrm{~V}$ & $\Delta \mathrm{V}_{1} \leq 1 \%$ \\
\hline
\end{tabular}

The proposed design methodology was based on PFM control method for CLLC-BRC. The initial transformer ratio $n$ could be set as $V_{1 N} / V_{2 N}$, and then normalized DC gain ranges $\left[G_{f m i n}, G_{f m a x}\right]$ of the forward mode and $\left[G_{r m i n}, G_{r m a x}\right]$ of the reverse mode were obtained with ripples and voltage drop on $\mathrm{GaN}$ transistors taken into account. Then, we preset a minimal normalized operating frequency $f_{\min }$.

Figure 7 shows the relation between normalized DC gain and normalized operating frequency $\mathrm{f}$ (Table 1) in the bidirectional modes under parameter sweep of quality factor with $\mathrm{L}_{\mathrm{n}}=2.6$ and $\mathrm{C}_{\mathrm{n}}=1.5$. Apparently, the rise in quality factor les to a drop in the whole level of dc gain, and the whole level of $G_{r}$ was higher than that of $G_{f}$. Therefore, it is important to guarantee that $G_{f m a x}$ is reached when $Q_{1}$ reaches its designed maximum $Q_{1 \max }$ and $f=f_{\min }$. Assuming $Q_{1 \max }=0.4$, it is clear that $G_{\text {fmax }}$ should be slightly below $G_{r \max }$, otherwise it cannot be reached when $Q_{1}=Q_{1 \max }$ and $f=f_{\min }$, which leads to adjusting the ratio $n$ properly. 


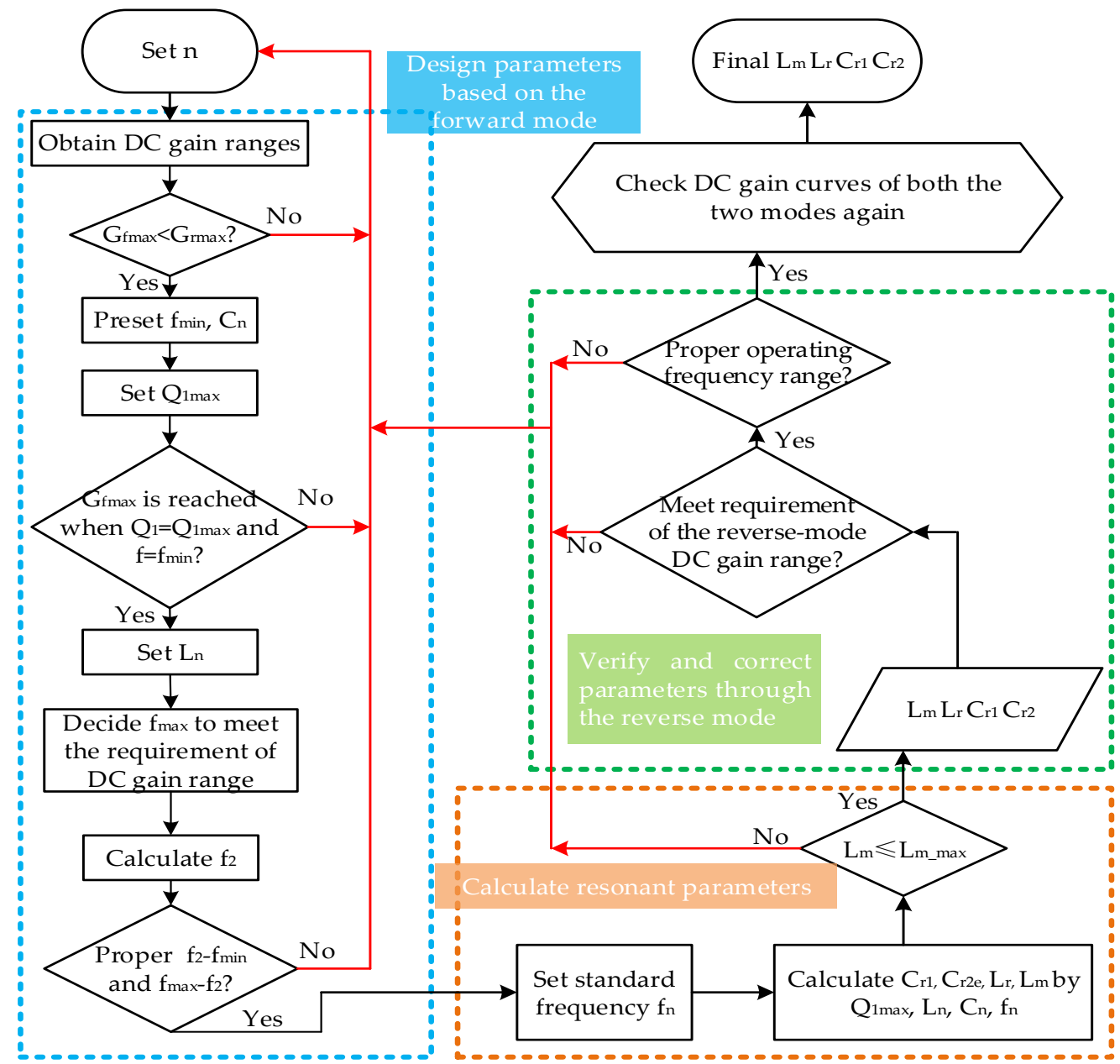

Figure 6. Flow chart of designing GaN-based CLLC-BRC.

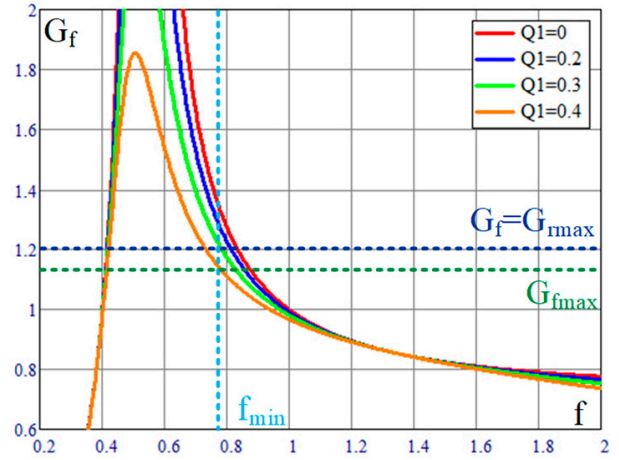

(a)

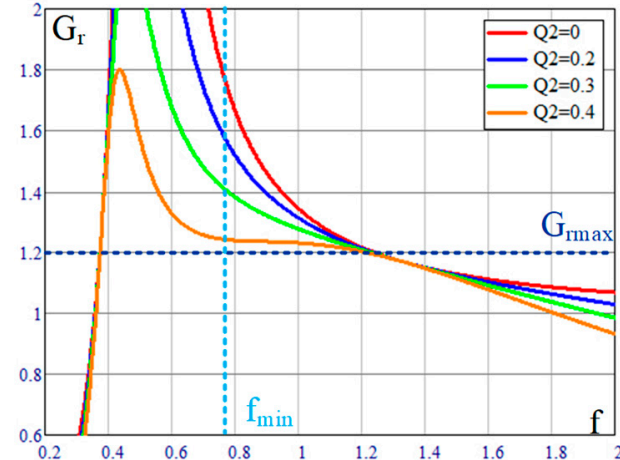

(b)

Figure 7. $\mathrm{DC}$ gain curves with parameter sweep of $\mathrm{Q}_{1}$ and $\mathrm{Q}_{2}$ to illustrate the requirement of $\mathrm{G}_{\text {fmax }}<\mathrm{G}_{\text {rmax }}$. (a) Forward mode; (b) reverse mode.

After ratio $n$ and $f_{\min }$ was obtained, we preset a $C_{n}$. Then, $Q_{1 \max }$ and $L_{n}$ needed setting. It was better to obtain the curves of relation between $Q_{1 \max }$ and peak normalized DC gain $\mathrm{G}_{\text {fpeak }}$ of the forward mode with parameter sweep of $L_{n}$, as shown in Figure 8a. Setting $L_{n}$ was limited by $\mathrm{G}_{\text {fpeak }}>\mathrm{G}_{\mathrm{fmax}}$, which shall be considered when setting $\mathrm{Q}_{1 \max }$. A proper $\mathrm{L}_{n}$ can be further decided by Figure $8 \mathrm{~b}$ after $\mathrm{Q}_{1 \max }$ is set. It needed to be guaranteed that the forward-mode dc gain range $\left[G_{f \min }, G_{f m a x}\right]$ was met within $\left[f_{\min }, f_{\max }\right]$, where $f_{\max }$ was the designed maximal normalized operating 
frequency. In other words, $\mathrm{f}_{\max }$ was determined by $\mathrm{L}_{\mathrm{n}}$ and the requirement of $\mathrm{DC}$ gain range. It was well expected that $f_{\min }$ and $f_{\max }$ are not far away from the normalized resonant frequency $f_{2}$ decided by $L_{n}$ and $C_{n}$ to decrease loss. A drop in $L_{n}$ will lead to a rise in the steepness of the gain curve and thus decrease in $\left|f_{\max }-f_{\min }\right|$, but it will also lead to rise in excitation current and dead-time loss. If it is hard to get proper $Q_{1 \max }$ and $L_{n}$, the previous steps need to be redone. It was noted that $C_{n}$ needed to be further verified and adjusted in combination with the reverse mode due to its effect on $\mathrm{f}_{\mathrm{m} 2}$.

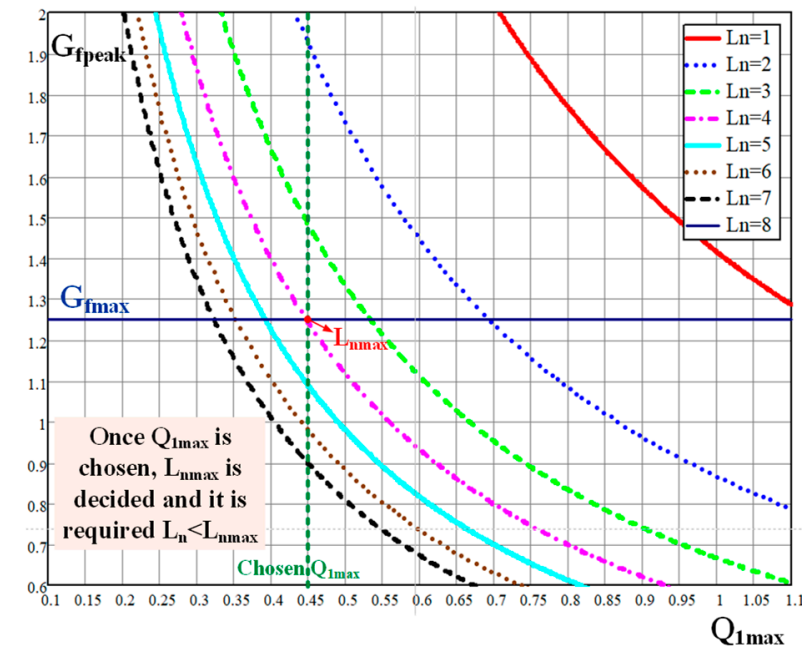

(a)

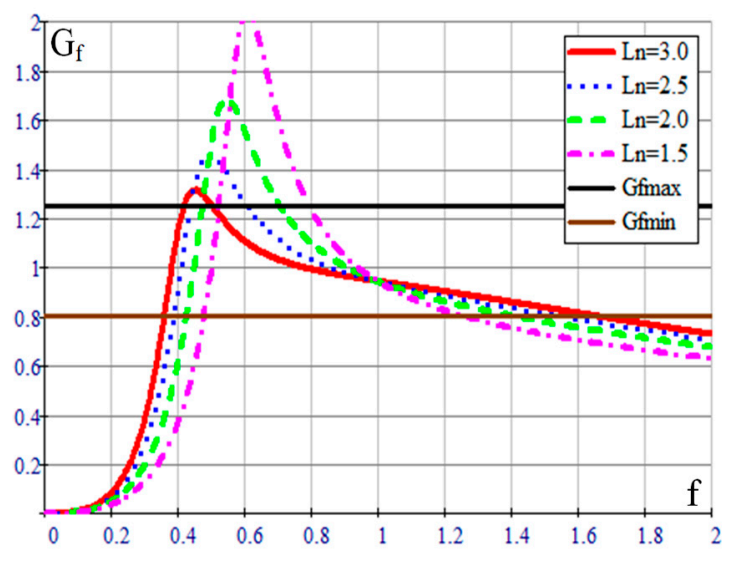

(b)

Figure 8. Gain curves used to determine $Q_{1 \max }$ and $L_{n}$. (a) Curve family of DC gain curves with various $Q_{1 \max }$ and $L_{n} ;(\mathbf{b})$ Curve family of DC gains with various $f$ and $L_{n}$.

In order to get the actual frequency range, basic frequency $f_{n}$ needed to be set. According to the ceiling of operating frequency $f_{\text {smax }}, f_{n}$ is determined by:

$$
\mathrm{f}_{\mathrm{n}}=\frac{1}{2 \pi \sqrt{\mathrm{L}_{\mathrm{r}} \mathrm{C}_{\mathrm{r} 1}}}=\frac{\mathrm{f}_{\mathrm{smax}}}{\mathrm{f}_{\max }}
$$

Therefore, values of $L_{m}, L_{r}, C_{r 1}$ and $C_{r 2}$ could be derived from $L_{n}, C_{n}, Q_{1 \max }, f_{n}$ and relevant expressions. Then, it needed to be verified whether $\mathrm{L}_{m}$ satisfied condition (19), and measure the gain curve of the reverse mode, which can be adjusted according to the above design rules. It should be pointed out that the adjustment of any parameter will affect the forward and reverse DC gains at the same time, and a better design result can only be obtained by continuous adjustment.

\subsection{Parameters of the Prototype}

According to the previous analysis, the ratio of the transformer could be set as $n=7$, and the parameters of the resonant elements are shown in Table 3, where the voltage and current stress could be obtained by the FHA method. The working-frequency ranges were [298 kHz, $472 \mathrm{kHz}]$ of the forward mode and $[271 \mathrm{kHz}, 548 \mathrm{kHz}]$ of the reverse mode. The values of resonant frequencies were: $\mathrm{f}_{\mathrm{m} 1}=131.60 \mathrm{kHz}, \mathrm{f}_{\mathrm{m} 2}=164.09 \mathrm{kHz}, \mathrm{f}_{\mathrm{r} 1}=106.09 \mathrm{kHz}$, and $\mathrm{f}_{\mathrm{r} 2}=407.08 \mathrm{kHz}$.

Table 3. Parameters of the resonant elements.

\begin{tabular}{cccc}
\hline Element & Value & Voltage Stress & Current Stress/RMS \\
\hline $\mathrm{C}_{\mathrm{r} 1}$ & $8.0 \mathrm{nF}$ & $253 \mathrm{~V}$ & $2.69 \mathrm{~A}$ \\
$\mathrm{C}_{\mathrm{r} 2}$ & $812.6 \mathrm{nF}$ & $21 \mathrm{~V}$ & $20.51 \mathrm{~A}$ \\
$\mathrm{~L}_{\mathrm{r}}$ & $29.4 \mu \mathrm{H}$ & $210 \mathrm{~V}$ & $2.69 \mathrm{~A}$ \\
$\mathrm{~L}_{\mathrm{m}}$ & $88.2 \mu \mathrm{H}$ & $626 \mathrm{~V}$ & $2.96 \mathrm{~A}$ \\
\hline
\end{tabular}




\section{Experimental Verification}

The structure of the prototype is shown in Figure 9, with its performance shown in Table 2, and its main components shown in Table 4. It used TI's UCD138 as a digital controller of the converter on the control board. Compared with the DSP/MCU completely managed by software like TMS320F28335 used in [9], UCD138 has access to high-speed control circuit, multi-loop control and solution of SR, with its three modes switched automatically to meet the requirement of SR in variable frequencies. In the high-voltage side, the isolated driving chip Si8273 was accepted to drive GaN transistors. In the low-voltage side, the non-isolated chip TI's LMG1205YFXR was used as a driver. The dead time was set as $100 \mathrm{~ns}$ based on the used GaN transistors.

One of the biggest obstacles for application of $\mathrm{GaN}$ transistors is to design the driving circuit properly, which is discussed in [21] in detail. Meanwhile, it was necessary to implement SR for the rectifier-side GaN transistors due to its comparatively large reverse voltage drop. On-time of rectifier-side GaN transistors can be set as $1 /\left(2 f_{r 2}\right)$ when the operating frequency $f_{s}$ is below $f_{r 2}$ and as $1 /\left(2 f_{s}\right)$ when $f_{s} \geq f_{r 2}$, derived from the principles of CLLC-BRC in [14].

The experimental results show that the operating frequency range was $[312 \mathrm{kHz}, 435 \mathrm{kHz}]$ of the forward mode, and it was [ $303 \mathrm{kHz}, 556 \mathrm{kHz}$ ] of the reverse mode. Main waveforms at the maximal and minimal operating frequencies of the two modes are shown in Figures 10 and 11, where $i_{\text {Lr }}$ is the current of the high-voltage side and $\mathrm{i}_{\mathrm{Tr} 2}$ is the current of the low-voltage side. ZVS of GaN transistors of the whole operating frequency range in the inverter side can be realized in both the two modes. $\mathrm{ZCS}$ of GaN transistors in the rectifier side can be realized when $\mathrm{f}_{\mathrm{s}}<\mathrm{f}_{\mathrm{r} 2}$, but cannot be realized when $f_{s}>f_{r 2}$, as shown in Figure 10c,d for the forward mode and in Figure 11c, d for the reverse mode. As shown in Figure 12, the converter achieved a maximal efficiency of $97.02 \%$ in the forward mode with the output power of $384 \mathrm{~W}$, and achieved a maximal efficiency of $95.96 \%$ in the reverse mode with the output power of $408 \mathrm{~W}$. Efficiency of more than $95 \%$ was achieved near the rated power of $400 \mathrm{~W}$ in the two modes.

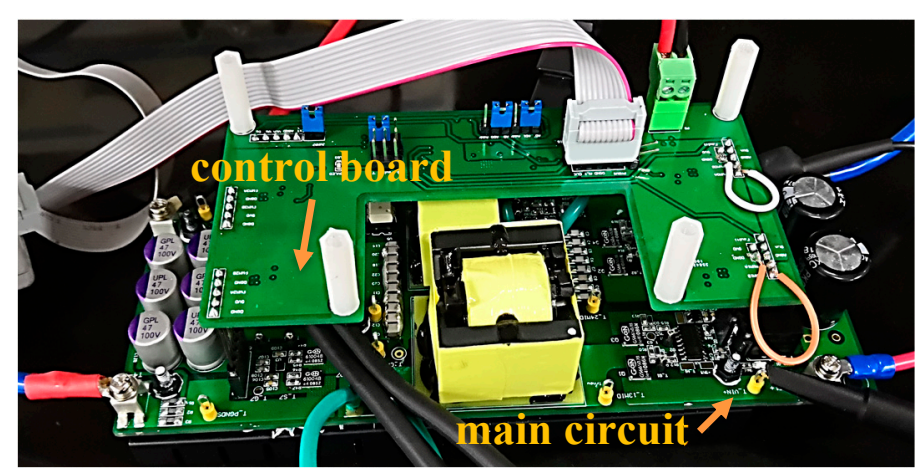

Figure 9. Structure of the prototype.

Table 4. Main components of the prototype.

\begin{tabular}{|c|c|c|}
\hline Components & Description & Quantity \\
\hline \multirow{2}{*}{ GaN transistors } & GS66502B, in the high-voltage side & 4 \\
\hline & GS61004B, in the low-voltage side & 4 \\
\hline $\mathrm{C}_{\mathrm{r} 1}$ & $1 \mathrm{nF}, 630 \mathrm{~V}$ & 8 \\
\hline & $47 \mathrm{nF}, 100 \mathrm{~V}$ & 17 \\
\hline $\mathrm{C}_{\mathrm{r} 2}$ & $6.8 \mathrm{nF}, 100 \mathrm{~V}$ & 2 \\
\hline $\mathrm{C}_{11}$ & $47 \mathrm{uF}, 450 \mathrm{~V}$, series & 2 \\
\hline $\mathrm{C}_{22}$ & $47 \mathrm{uF}, 100 \mathrm{~V}$, parallel & 3 \\
\hline HF Transformer & $\begin{array}{c}\text { Wound-type; } \mathrm{n}=7: 1 ; \text { Primary } \mathrm{L}_{\mathrm{m}}=88.2 \mu \mathrm{H} ; \\
\text { Core material:DRM95 }\end{array}$ & 1 \\
\hline
\end{tabular}




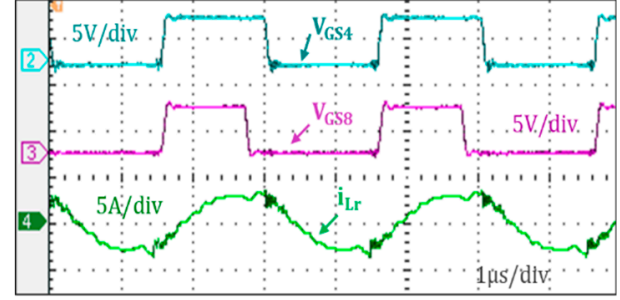

(a)

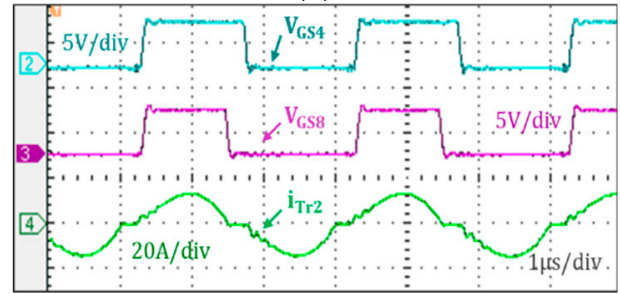

(c)

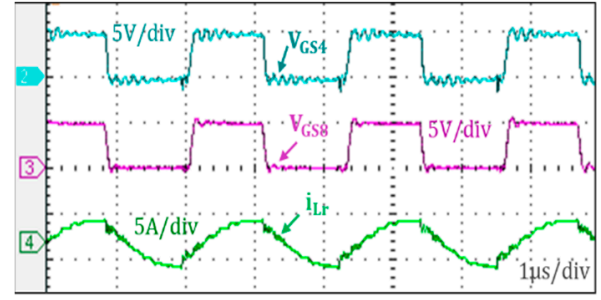

(b)

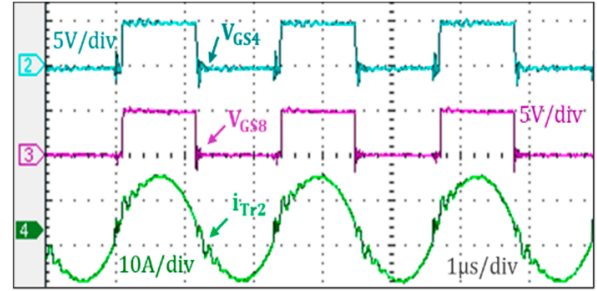

(d)

Figure 10. Main experimental waveforms of the forward mode. (a) Waveform of $i_{\mathrm{Lr}}$ when $\mathrm{f}_{\mathrm{S}}=312 \mathrm{kHz}$; (b) waveform of $i_{L r}$ when $f_{s}=435 \mathrm{kHz}$; (c) waveform of $i_{T r 2}$ when $f_{s}=312 \mathrm{kHz}$; (d) waveform of $i_{\operatorname{Tr} 2}$ when $\mathrm{f}_{\mathrm{s}}=435 \mathrm{kHz}$.

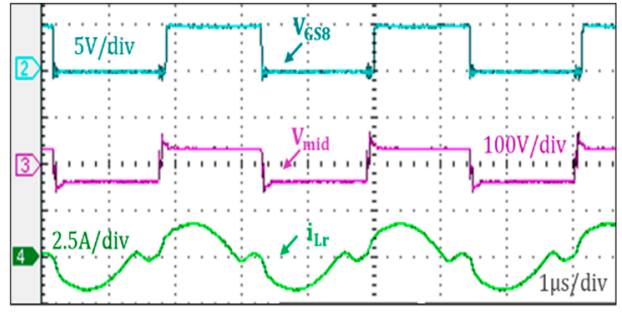

(a)

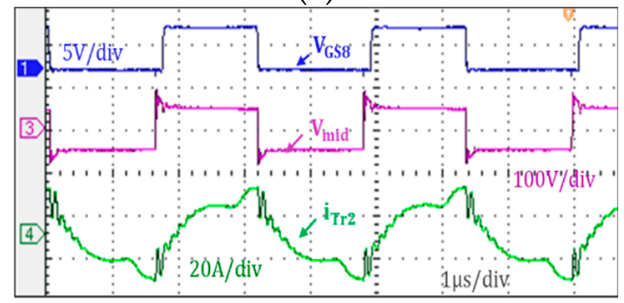

(c)

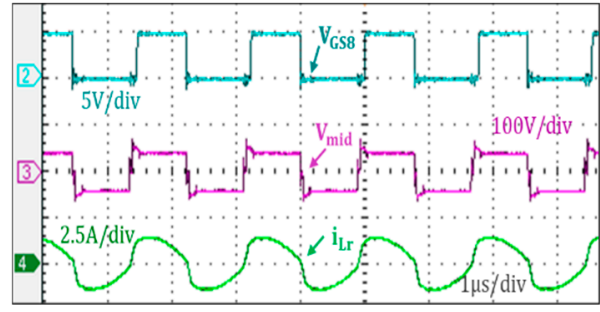

(b)

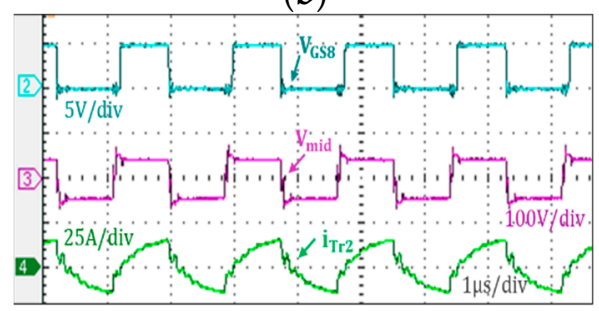

(d)

Figure 11. Main experimental waveforms of the reverse mode. (a) Waveform of $i_{L r}$ when $f_{s}=303 \mathrm{kHz}$; (b) waveform of $i_{\text {Lr }}$ when $f_{s}=556 \mathrm{kHz}$; (c) waveform of $i_{\operatorname{Tr} 2}$ when $f_{s}=303 \mathrm{kHz}$; (d) waveform of $i_{\text {Tr2 }}$ when $\mathrm{f}_{\mathrm{s}}=556 \mathrm{kHz}$.

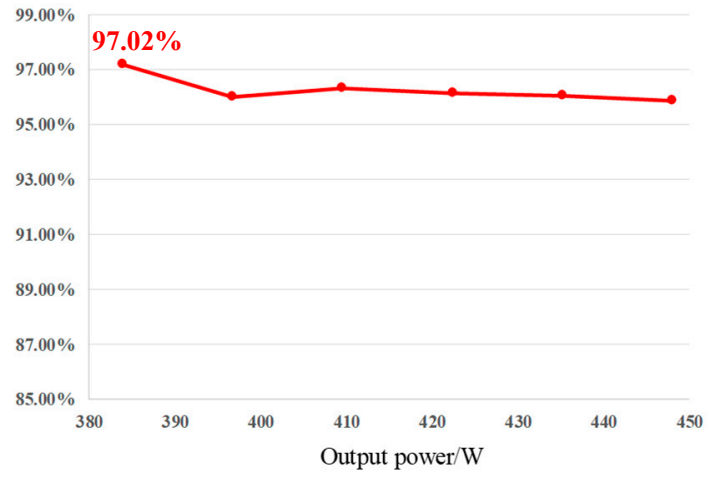

(a)

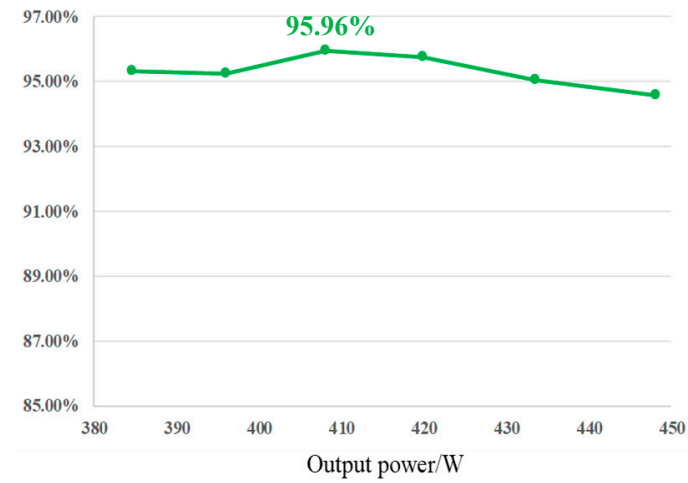

(b)

Figure 12. Efficiency curves of the converter. (a) Forward mode; (b) reverse mode. 


\section{Conclusions}

GaN transistors have the advantages of low on-resistance and parasitic parameters, fast switching speed, low reverse recovery loss and so on. The application of $\mathrm{GaN}$ transistors can further improve the frequency, efficiency and power density of the DC-DC converters. In contrast to GaN-based bidirectional CLLLC resonant converters, one resonant inductance was removed in CLLC-BRC, resulting in less loss of resonant components, less volume and more convenience for the design and control of the converter, with similar features of bidirectional conversion preserved. In the bidirectional operating modes of CLLC-BRC, zero-voltage switching of the inverter-side switches was realized under all load conditions, while zero-current switching of the rectifier-side switches was realized within a certain load range. In contrast to [14], more thorough analysis of CLLC-BRC with solution of resonant frequencies and improved ZVS condition is given in this paper. Also, more explicit and comprehensive design methodology based on PFM is displayed, with the whole level of operating frequency improved by GaN transistors. Experimental results of the prototype with a rated power of $400 \mathrm{~W}$ have proved the validity of proposed design methodology, with the SR method for rectifier-side switches provided. The peak efficiency of the prototype was $97.02 \%$ in the forward mode, and $95.96 \%$ in the reverse mode, with the maximal operating frequency that is larger than $0.5 \mathrm{MHz}$.

Author Contributions: Conceptualization, Y.L. (Yuanjun Liu); Formal analysis, Y.L. (Yuanjun Liu) and X.W.; Funding acquisition, G.D.; Investigation, Y.L. (Yuanjun Liu) and X.Y.; Supervision, G.D.; Validation, Y.L. (Yuanjun Liu) and G.D.; Writing—original draft, Y.L. (Yuanjun Liu); Writing—review \& editing, Y.L. (Yuanjun Liu), G.D., X.W. and Y.L. (Yanxiong Lei).

Funding: This research was funded by Natural Science Foundation of Guangdong Province, China, grant number 2017B030312001.

Conflicts of Interest: The authors declare no conflict of interest.

\section{References}

1. Wu, M.; Flynn, D.; Szymczak, A. Design and implementation of ZVZCS in full bridge DC/DC converter with digital control in arc welding machines application. In Proceedings of the IEEE International Symposium on Industrial Electronics, Edinburgh, UK, 19-21 June 2017.

2. Kato, H.; Matsuo, H.; Ito, T.; Kawazu, S.; Kawahara, D.; Motomura, S.; Hamaguchie, R. Comparative analysis of full bridge and half bridge current resonant DC-DC converter. In Proceedings of the 33rd International Telecommunications Energy Conference (INTELEC), Amsterdam, The Netherlands, 9-13 October 2011.

3. Kundu, U.; Yenduri, K.; Sensarma, P. Accurate ZVS Analysis for Magnetic Design and Efficiency Improvement of Full-Bridge LLC Resonant Converter. IEEE Trans. Power Electron. 2016, 32, 1703-1706. [CrossRef]

4. Joung, M.; Kim, H.; Baek, J. Dynamic analysis and optimal design of high efficiency full bridge LLC resonant converter for server power system. In Proceedings of the Applied Power Electronics Conference and Exposition, Orlando, FL, USA, 5-9 February 2013.

5. Severns, R.P. Topologies for three-element resonant converters. IEEE Trans. Power Electron. 1992, 7, 89-98. [CrossRef]

6. Jung, J.H.; Kim, H.S.; Ryu, M.H.; Baek, J.W. Design Methodology of Bidirectional CLLC Resonant Converter for High-Frequency Isolation of DC Distribution Systems. IEEE Trans. Power Electron. 2013, 28, 1741-1755. [CrossRef]

7. Dalala, Z.M.; Zahid, Z.U.; Saadeh, O.S.; Lai, J.S. Modeling and Controller Design of a Bidirectional Resonant Converter Battery Charger. IEEE Access 2018, 6, 23338-23350. [CrossRef]

8. Jung, J.H.; Kim, H.S.; Kim, J.H.; Ryu, M.H.; Baek, J.W. High efficiency bidirectional LLC resonant converter for 380V DC power distribution system using digital control scheme. In Proceedings of the Applied Power Electronics Conference \& Exposition, Orlando, FL, USA, 5-9 February 2012; IEEE: Piscataway, NJ, USA, 2012.

9. He, P.; Mallik, A.; Sankar, A.; Khaligh, A. Design of a 1-MHz High-Efficiency High-Power-Density Bidirectional GaN-Based CLLC Converter for Electric Vehicles. IEEE Trans. Veh. Technol. 2019, 68, 213-223. [CrossRef]

10. Zahid, Z.U.; Dalala, Z.M.; Chen, R.; Chen, B.; Lai, J.S. Design of Bidirectional DC-DC Resonant Converter for Vehicle-to-Grid (V2G) Applications. IEEE Trans. Transp. Electrif. 2015, 1, 232-244. [CrossRef] 
11. Zou, S.; Lu, J.; Mallik, A.; Khaligh, A. Bi-Directional CLLC Converter with Synchronous Rectification for Plug-In Electric Vehicles. IEEE Trans. Ind. Appl. 2018, 54, 998-1005. [CrossRef]

12. Chen, Q. Research on Key Technologies of Bidirectional CLLLC Resonant Converters. Ph.D. Thesis, Harbin Institute of Technology, Harbin, China, June 2015.

13. Chen, W.; Wang, S.; Hong, X.; Lu, Z.; Ye, S. Fully Soft-switched Bidirectional Resonant DC-DC Converter with A New CLLC Tank. In Proceedings of the Applied Power Electronics Conference \& Exposition, Palm Springs, CA, USA, 21-25 February 2010; IEEE: Piscataway, NJ, USA, 2010.

14. Chen, W.; Rong, P.; Lu, Z. Snubberless Bidirectional DC-DC Converter with New CLLC Resonant Tank Featuring Minimized Switching Loss. IEEE Trans. Ind. Electron. 2010, 57, 3075-3086. [CrossRef]

15. Mu, M.; Lee, F.C. Design and Optimization of a 380-12 V High-Frequency, High-Current LLC Converter with GaN Devices and Planar Matrix Transformers. IEEE J. Emerg. Sel. Top. Power Electron. 2016, 4, 854-862.

16. Zhang, W.; Wang, F.; Costinett, D.J.; Tolbert, L.M.; Blalock, B.J. Investigation of Gallium Nitride Devices in High-Frequency LLC Resonant Converters. IEEE Trans. Power Electron. 2017, 32, 571-583. [CrossRef]

17. Xiang, J.; Ren, X.; Wang, Y.; Zhang, Y. Investigation of cascode stucture GaN devices in ZCS region of LLC resonant converter. In Proceedings of the 2017 IEEE Energy Conversion Congress and Exposition (ECCE), Cincinnati, OH, USA, 1-5 October 2017; pp. 1374-1378.

18. Chen, R.; Yu, S.Y. A high-efficiency high-power-density $1 \mathrm{MHz}$ LLC converter with GaN devices and integrated transformer. In Proceedings of the 2018 IEEE Applied Power Electronics Conference and Exposition (APEC), San Antonio, TX, USA, 4-8 March 2018; IEEE: Piscataway, NJ, USA, 2018.

19. Fei, C.; Gadelrab, R.; Li, Q.; Lee, F.C. High-Frequency Three-Phase Interleaved LLC Resonant Converter with GaN Devices and Integrated Planar Magnetics. IEEE J. Emerg. Sel. Top. Power Electron. 2019, 7, $653-663$. [CrossRef]

20. Fu, M.; Fei, C.; Yang, Y.; Li, Q.; Lee, F.C. Optimal Design of Planar Magnetic Components for a Two-Stage GaN-Based DC-DC Converter. IEEE Trans. Power Electron. 2019, 34, 3329-3338. [CrossRef]

21. GaN Systems: How to Drive GaN Enhancement Mode HEMT. Available online: http://www.gansystems. com/whitepapers.php (accessed on 24 March 2016).

(C) 2019 by the authors. Licensee MDPI, Basel, Switzerland. This article is an open access article distributed under the terms and conditions of the Creative Commons Attribution (CC BY) license (http://creativecommons.org/licenses/by/4.0/). 